\title{
Primeiro Assinalamento de Scutellonema bradys em Dioscorea alata no Brasil, Estabelecido no Estado de São Paulo
}

\author{
Romero M. Moura ${ }^{1}$, Idjane S. Oliveira ${ }^{1}$ \& Gustavo Rubens C. Torres ${ }^{1}$ \\ ${ }^{1}$ Departamento de Ciências Biológicas, Universidade Estadual de Santa Cruz, CEP 45600-000, Ilhéus, BA, \\ e-mail: romeromoura@yahoo.com.br
}

(Aceito para publicação em 11/11/2005)

Autor para Correspondência: Romero Marinho de Moura

\begin{abstract}
First report on the occurrence of Scutellonema bradys on Dioscorea alata in Brazil, established in the State of São Paulo

This paper reports the first occurrence of the dry rot on Dioscorea alata in Brazil and the occurrence of this disease and the yam nematode Scutellonema bradys, the causal agent, in the State of São Paulo.
\end{abstract}

No Brasil, duas espécies de inhame são as mais utilizadas como culturas alimentícias; Dioscorea cayennensis Lam. e D. alata L. com as respectivas cultivares "da Costa" e "São Tomé". A primeira é cultivada no Nordeste e a segunda no norte, sul e centro sul, sendo São Paulo o mais importante estado produtor, onde a cultura é conhecida por cará. Nematóides e fungos causam severas doenças do inhame no mundo inteiro, inclusive no Brasil [Moura, 2005. Doenças do Inhame. In: Kimati et. al. (Eds.) Manual de Fitopatologia. v. 2. Doenças das Plantas Cultivadas. São Paulo SP. Ceres]. Entre essas, com alto destaque, situa-se a casca preta, conhecida na literatura internacional por dry rot of yam, causada, isoladamente, pelos nematóides Scutellonema bradys Steiner, LeHew \& Andrassy, conhecido por the yam nematode, e Pratylenchus coffeae Filipjev \& Stekhoven, the lesion nematode, não havendo referências sobre infecções mistas. Esses patógenos se estabelecem nas raízes de alimentação e periferia das túberas comerciais e sementes, aprofundando-se até $5 \mathrm{~cm}$, Figura 1A. Como conseqüências do parasitismo, as túberas diminuem o volume, peso e a qualidade de mercado. Os fitonematóides provocam também ferimentos na epiderme, que são fatores de predisposição à incidência do fungo Penicillium sclerotigenum Yamamoto, agente etiológico da podridão-verde, doença responsável por elevadas perdas durante o armazenamento. No Brasil, não houve, até o momento, assinalamento da casca preta fora do Nordeste nem em $D$. alata, estando a doença restrita a D. cayennensis. Esse fato indicava uma provável imunidade da cultivar "São Tomé", muito embora trabalhos internacionais já houvessem relatado a suscetibilidade de $D$. alata em relação aos nematóides causadores da casca preta, exemplo de Jatala \& Bridge, 1990 [Nematode parasites of root and tuber crops. In: Luc et al., (Eds.) Plant Parasitic Nematodes in Subtropical and Tropical Agriculture. Wallingford. CAB International. p. 137] Nesses trabalhos nunca foram mencionados nomes das variedades ou cultivares susceptíveis. Em julho de 2005, foram analisadas dez túberas de inhame cv. "São Tomé", coletadas em campos de produção da empresa Agroexotic Comércio Exterior LTDA, localizados no município de Planalto, próximo de São José do Rio Preto, encaminhadas ao Recife pelo Eng. Agro. José Luiz M. Garcia, técnico da empresa, para análise fitopatológica. Segundo relato dos técnicos responsáveis pelas coletas, foram identificadas no campo diversas reboleiras que somavam aproximadamente $4 \mathrm{hc}$, onde haviam evidências da ocorrência de casca preta. Após as extrações de nematóides de tecidos de túberas infetadas, as analises morfológica e morfométrica de espécimes machos e fêmeas de um tipo de nematóide encontrado em associação constante com a doença confirmaram o diagnóstico e permitiram a identificação do agente causal como sendo o endoparasito migrador S. bradys (Figura $1 \mathrm{~B}$ ), presente em elevadíssimo número por grama de tecido. Além de evidenciar um grave problema fitopatológico, provavelmente introduzido por túberas-sementes contaminadas, este trabalho faz o primeiro assinalamento de S. bradys em $D$. alata no Brasil e também o primeiro das ocorrências da casca preta e do nematóide $S$. bradys no Estado de São Paulo.

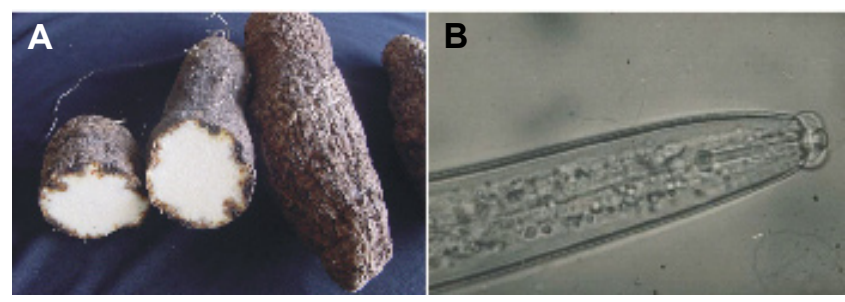

FIG. 1 - A. Sintomas externos e internos da doença casca preta em túberas comerciais de Dioscorea alata cultivar "São Tomé", coletadas no Estado de São Paulo; B. Região anterior do nematóide Scutellonema bradys. 